\title{
Accessibility Considerations for e Learning in Ghana
}

\author{
John Kwame Boateng ${ }^{1}$ \\ ${ }^{1}$ School of Continuing and Distance Education, \\ University of Ghana Learning Centers, Legon, Accra, \\ Ghana
}

\section{Abstract}

This paper reports on a study that explored the best ways to design e learning in order to provide better access for adult learners with disabilities. Two districts from the Central Region of Ghana were selected and two major research questions guided the study. The five-point Likert scale was employed between May and August of 2014. The two questions asked were: The kind of issues that should be taken into account in the design and management of accessible e learning? And what problems need be resolved to have accessibility solutions for e-learning by the diverse adult learner population in the region? The results confirm existing insights about accessibility considerations in Ghana, other African countries and the world at large for the disabled, showing that Ghana and other African countries are not unique in terms of accessibility requirements in designing e learning in order to provide better access for adult learners with disabilities.

Keywords: Accessibility, Disabled learners, Communication handling, Learning attainment, Web interface accessibility.

\section{Contents}

1. Introduction.

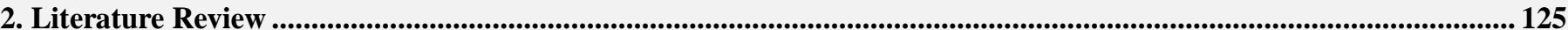

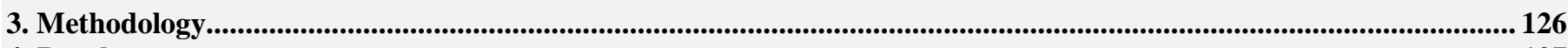

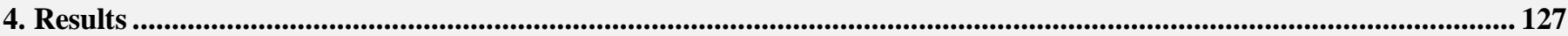

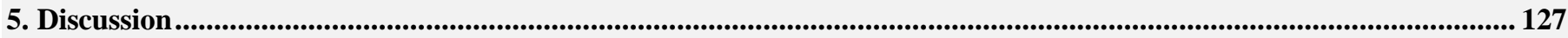

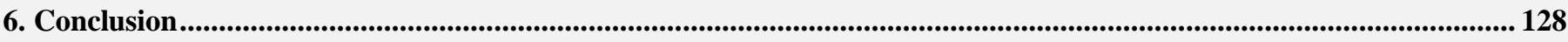

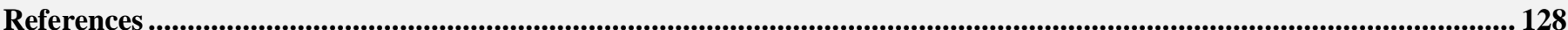

Citation | John Kwame Boateng (2016). Accessibility Considerations for e Learning in Ghana. Journal of Education and e-Learning Research, 3(4): 124129 .

DOI:

$\operatorname{ISSN}(\mathbf{E})$ :

ISSN(P):

Licensed:

Funding: $\quad$ The, Office of Research Innovation and Development (ORID), the University of Ghana and the University of Michigan, African

10.20448/journal.509/2016.3.4/509.4.124.129 Crossref $2410-9991$

2518-0169 Presidential Scholars (UMAPS) Program of the African Studies Center, University of Michigan, supported the study.

Competing Interests: The author declares that there are no conflicts of interests regarding the publication of this paper.

Transparency: The author confirms that the manuscript is an honest, accurate, and transparent account of the study was reported; that no vital features of the study have been omitted; and that any discrepancies from the study as planned have been explained.

History: $\quad$ Received: 2 September 2016/ Revised: 16 November 2016/ Accepted: 22 November 2016/ Published: 26 November 2016

Ethical:

This study follows all ethical practices during writing.

Publisher: $\quad$ Asian Online Journal Publishing Group 


\section{Introduction}

This study was motivated by some questions pertaining to management interfaces of modern e-learning system and environment \{well designed interfaces like good educators and instructional materials should build a teacherstudent relationship that guides users to learn and enjoy what they do Shojafar et al. (2015) \} and how to comply with accessibility guidelines \{accessibility guidelines eexplain how to make user agents accessible to people with disabilities, particularly to increase accessibility to web content.

User agents include Web browsers, media players and assistive technologies which are software that some people with disabilities use in interacting with computers (WCAG, 2008)\} and whether the application of such guidelines primarily aligns with the student, or content-user interface to the system in an attempt by the School of Continuing and Distance Education of the University of Ghana to respond effectively to the needs of adult learners in the use of instructional design technology for developing essential knowledge, skills, and attitudes for lifelong learning. The current study asked the following two questions: What are the kind of issues that should be taken into account in the design and management of accessible e learning in the Central Region of Ghana? What problems need be resolved to have accessiibility solutions for e-learning by the diverse adult learner population in the region?

According to the UNESCO Institute for Statistics, (2007) cited by Asunka (2008) in sub-Saharan Africa, it is estimated that only 1 in 250 people have access to the Internet as against the global average of 1 in 15 Furthermore, Asunka (2008) citing Saint, (1999) show that online learning in higher education in sub-Saharan Africa poses a great challenge as this mode of instruction delivery relies solely on the available information and communication technology infrastructure and the fact that most institutions within the sub-region are currently in a state of crises having to cope with collapsing infrastructure, brain drain, and dwindling financial resources, whilst under increasing pressure to cater for larger student populations.

Despite these constraints, online learning is still being touted as the only and best possible solution to the problem of access to quality higher education in Sub-Saharan Africa (Asunka, 2008). Although, online learning has been seen to benefit everyone, students with disabilities still experience web barriers that prevent them from benefiting from online learning (Ndeya-Nderera, 2012). Such students according to Ndeya-Ndereya often struggle with some aspects of learning because most online courses are not accessible to students with disabilities. According to Burgstahler et al. (2004) courses that are designed to be accessible to all potential students, including those with disabilities, offer opportunities to level the playing fields for people with disabilities. Furthermore, Dell et al. (2015). observe that engaging in accessible course design has been proven to be a proactive approach in which online courses are created, taking into consideration the needs of diverse learners (in age, gender, backgrounds, learning styles, abilities and disabilities.

Bugler (2013) revealed that crucial assistive technology in education ranges from low-tech options such as reading stands to high-cost computer technology such as Braille display. She further showed that although text-tospeech software has vastly improved opportunities for those with disabilities to engage with ICTs, the real deal comes in the shape of hardware complete with loudspeakers, a Braille keyboard and screen-reader software which converts all text on a screen to audio output. She noted that, all these assistive technologies come at a great cost and wondered how African educational Institutions could make accessibility in online learning a reality for the disabled.

\section{Literature Review}

Cooper et al. (2007) makes it clear that, if e-learning research and development projects are to be successfully adopted in the real-world teaching and learning contexts, they must effectively address accessibility and usability issues.

\subsection{Defining Accessibility}

Accessibility has been defined as the design of products, devices, services or environments for people who experience disabilities (Henry et al., 2014). Henry (2001) defined accessibility as the ability for a person to be able use a product when they are experiencing functional limitations. According to Valdes (2003) the concept of accessible design and the associated practice of accessible development enables both direct (unassisted) access and indirect (assisted) access. Indirect access implies compatibility with an individual's assistive technology such as computer screen readers. Accessibility focuses on enabling of access for people with disabilities. Research and development in accessibility brings benefit to everyone. Accessibility is not usability though closely related. Usability is the extent to which a product such as a device, a service or an environment can be used by specified users to achieve specified goals with effectiveness, efficiency and satisfaction in a specified context of use (Wikipedia, 2016).

Henry (2001) showed that accessible products can be used by more people, more effectively and in more situations. User-centered design (UCD) is a user interface (UT) design process that considers usability goals, user characteristics, environment tasks and workflow in the design of an interface.

The Lincolnshire County Council (2010) defined accessibility as the process that aims to promote social inclusion by helping people from disadvantaged groups or areas access jobs and essential services. Accessibility focuses on making things usable by people with disabilities, including temporary disabilities. Accessibility has also been defined as the ability of the learning environment to adjust to the needs of all learners (IMS Global Learning Consortium, 2002). "Accessibility" is thus determined by the flexibility of the e-learning system or learning resource to meet the needs and preferences of all users. These needs and preferences may arise from their environment (e.g. working in a noisy environment), the tools they use (e.g. assistive technologies such as screen-readers, voicerecognition tools or alternative keyboards, etc.) or a disability in the conventional sense (Cooper et al., 2007). 


\subsection{Distinction between Accessibility and Usability}

Shneiderman (2000) observe that people with disabilities encounter all the same problems that people without disabilities do. According to Sloan et al. (2002) accessibility and usability are intrinsically linked. The lower the level of accessibility of a resource for an individual, the less usable it will be for them. In the worst case they will not be able to use it at all. Conversely, improved accessibility for disabled users promotes usability for all. Usability should play an important role in accessibility testing, since a resource presenting usability difficulties will generally present significant accessibility problems for disabled users. Even sites with a high level of accessibility can nevertheless have usability problems that may prevent people with disabilities from using them efficiently (Cooper $e t$ al., 2007).

\subsection{Students' Expectations and Experience}

Asunka (2008) show that, a cross-section of Ghanaian students studied in a private tertiary school did not respond favorably to online constructivist teaching approaches such as asynchronous discussions and ill-structured project-based learning activities, and perceived collaborative online learning within their context as a complex, more demanding and time-consuming experience. Many other studies have reported unfavourable students experiences with online learning stemming largely from improper planning and poor implementation and evaluation of e-learning approaches.

\section{Methodology}

This was an exploratory survey carried out to investigate accessibility issues and needs that confronts the diverse learner population in the Central Region (CR) of Ghana. This research was part of a bigger research carried out in the Central Region from May to August, 2014. The entire survey investigated six research questions as follows: The questions asked are:

1. What major challenges/opportunities do learners face in pursuing e- learning in CR?

2. What accessibility/usability issues are significant in e learning in CR?

3. What are the needs of working/ and non-working adults to pursue e learning in CR?

4. What are the needs of disabled learners to pursue e learning in CR?

5. What issues are discussed among system developers to provide accessible e-learning

6. How to become cost effective in e-learning taking into consideration issues about access to resources, accessibility and usability

In this paper only 2 of the 6 questions are addressed. Survey instruments for the current study addressed the research questions 2 and 4 . The survey instruments probed respondents about what accessibility issues are important in e learning for disabled learners. Specific issues considered in the survey instruments included; forms learning content takes, how assessments happen, how communication are handled, the design of e-learning systems, the functioning of the e-learning system interface, web interface accessibility, inclusive education options for the disabled, learning attainment and respondents' physical location. A second question considered by the survey instrument was the needs disabled learners' have effective e learning in Ghana. Under this question, specific issues investigated by the survey instruments included; training needs of disabled learners for e-learning support for text browsers on the world-wide web, alternate methods for online forms, information layouts that are consistent and easy to understand, simplified and consistent design and presentation, obtaining e-test versions of books, screen enlargements, appropriate text colors and highlights, provision of visual and aural presentation of materials and provision of organizational areas such as calendar task list address book

The survey questions were measured using a five-point Likert scale. It probed the extent to which adult learners in the Central Region agreed or disagreed with concerns and statements expressed about accessibility in e learning. The survey covered two districts in the Central Region namely, the Cape Coast Metropolitan Assembly and the Abura-Asebu-Kwamankese District.

\subsection{Population and Sample Sizes of the Study}

Population for the study comprised adult learners within the two Districts considered for the study in the Central Region. The study population was estimated to approximate between 500 and 600 adult learners in the two districts. The sample size was 150 . Two hundred questionnaire were distributed to respondents. One hundred and fifty were returned. Out of this number, 50 indicated to have some form of disability and 100 said they have no disability but know learners with disability. Only respondents who claimed to have experienced e learning at a point in their life were included in the study.

\subsection{Questionnaire Development}

The questionnaire employed Likert scale with five levels ranging from strongly agree (5 points), agree (4 points), uncertain ( 3 points) disagree ( 2 points) and strongly disagree (1point) was used.

\subsection{Validation of Instruments}

The instruments for the study was assessed for content and construct validity. Each item of the instrument was carefully analyzed and checked to ensure that it conveyed the necessary message.

\subsection{Data Entry and Analysis}

Quantitative data resulting from the survey was entered into the Statistical Package for Social Sciences (SPSS). Data entered was analyzed and mean responses were examined. Descriptive Statistics (means, charts and standard deviations) were used to present results. 


\section{Results}

Figure 1, shows respondents assessment on the various accessibility issues important in E-learning system in the Central Region of Ghana.

Table-1. Accessibility issues important in e-learning for learners in Ghana

\begin{tabular}{l|l|l|l|l|l}
\hline Accessibility issues & Strongly Disagree & Disagree & Uncertain & Agree & Strongly Agree \\
\hline Learning Attainment & $2(1.3 \%)$ & $20(13.3 \%)$ & $14(9.3 \%)$ & $65(43.3 \%)$ & $49(32.7 \%)$ \\
\hline Communication Handling & $2(1.3 \%)$ & $2(1.3 \%)$ & $9(6 \%)$ & $83(55.3 \%)$ & $54(36 \%)$ \\
\hline Web interface accessibility & $2(1.3 \%)$ & $10(6.7 \%)$ & $10(6.7 \%)$ & $64(42.7 \%)$ & $64(42.7 \%)$ \\
\hline Forms Learning content takes & $1(0.7 \%)$ & $4(2.7 \%)$ & $17(11.3)$ & $89(59.3 \%)$ & $39(26 \%)$ \\
\hline How assessment take place & $3(2 \%)$ & $4(2.7 \%)$ & $12(8 \%)$ & $92(61.3)$ & $39(26 \%)$ \\
\hline E-learning systems are designed for & $7(4.7 \%)$ & $14(9.3 \%)$ & $15(10 \%)$ & $49(32.7 \%)$ & $65(43.3 \%)$ \\
\hline E-learning systems interface function & $2(1.3 \%)$ & $7(4.7 \%)$ & $11(7.3 \%)$ & $88(58.7 \%)$ & $42(28 \%)$ \\
\hline $\begin{array}{l}\text { Inclusive education options for } \\
\text { disabled }\end{array}$ & $1(0.7 \%)$ & $6(4 \%)$ & $9(8 \%)$ & $85(56.7 \%)$ & $49(32.7 \%)$ \\
\hline Physical location & $1(0.7 \%)$ & $12(8 \%)$ & $13(8.7 \%)$ & $79(52.7 \%)$ & $45(30 \%)$ \\
\hline
\end{tabular}

Source: Field Survey by John Boateng, 2014

Of all the accessibility issues, respondents indicated that accessibility issues in terms of learning attainment (mean $=4.3$ ) was of major importance. Reporting in a frequency table the number of responses to each question and scale in $(\%)$ are shown in Table 1 . It was perceived by the study respondents that communication handling (mean $=$ 4.2), web interface accessibility (mean $=4.2$ ) and all other accessibility issues (inclusive education options for the disabled, mean $=4.2$; forms learning content takes, mean $=4.1$; how assessments take place, mean $=4.1$; E-learning system interface functioning, mean $=4.1$; physical location, mean $=4.0$ ) showed in the figure above were all important in E-Learning system.

The means of these responses clearly indicated their assessment. On assessing needs of disabled learners for elearning, respondents made it clear that providing them alternate methods for online forms (mean $=4.3)$ was the major priority. Respondents indicate provision of both visual and aural presentation of material $(\mathrm{mean}=4.2)$. Reporting in a frequency table the number of responses to each question and scale in (\%) are shown in Table 2. A simplified and consistent design and presentation of the e-learning platform (mean=4.2) and also providing them etest versions of books (mean= 4.2) for the disabled. Respondents perceived other needs mentioned are listed in the Table 2. They include: Support for text browsers on the world-wide-web, (mean $=4.1$ ); providing information layouts that are consistent and easy to understand (mean $=4.1)$; Screen enlargements (mean $=4.1$ ); providing appropriate text colors and highlights (mean $=4.1$ ) and providing areas for better organization such as calendar, task list and address book (mean $=3.9)$.

Table-2. Needs of disabled learners for e-learning in Ghana

\begin{tabular}{l|l|l|l|l|l}
\hline Needs of disabled learners & Strongly Disagree & Disagree & Uncertain & Agree & Strongly Agree \\
\hline $\begin{array}{l}\text { Training needs of disabled learners for } \\
\text { e-learning; support for text browsers } \\
\text { on the world-wide-web }\end{array}$ & $1(0.7 \%)$ & $6(4 \%)$ & $17(11.3 \%)$ & $82(54.7 \%)$ & $44(29.3 \%)$ \\
\hline Alternate methods for online forms & $1(0.7 \%)$ & $5(3.3 \%)$ & $17(11.3 \%)$ & $48(32 \%)$ & $79(52.7 \%)$ \\
\hline $\begin{array}{l}\text { Information layouts that are } \\
\text { consistent and easy to understand }\end{array}$ & 0 & $9(6 \%)$ & $14(9.3 \%)$ & $82(54.7 \%)$ & $45(30 \%)$ \\
\hline $\begin{array}{l}\text { Simplified and consistent design and } \\
\text { presentation }\end{array}$ & $7(4.7 \%)$ & $5(3.3 \%)$ & $7(4.7 \%)$ & $63(42.0 \%)$ & $68(45.3 \%)$ \\
\hline $\begin{array}{l}\text { Obtain e-test versions of books } \\
\text { Screen enlargement }\end{array}$ & $4(2.7 \%)$ & $6(4.0 \%)$ & $8(5.3 \%)$ & $71(47.3 \%)$ & $61(40.7 \%)$ \\
\hline Appropriate text colors and highlight & $2(1.3 \%)$ & $10(6.7 \%)$ & $12(8.0 \%)$ & $70(46.7 \%)$ & $57(38.0 \%)$ \\
\hline $\begin{array}{l}\text { Provision of both visual and aural } \\
\text { presentation of material }\end{array}$ & $4(2.7 \%)$ & $4(2.7 \%)$ & $17(11.3 \%)$ & $58(38.7 \%)$ & $67(44.7 \%)$ \\
\hline $\begin{array}{l}\text { Provision of organizational areas such } \\
\text { as calendar task list, address book etc. }\end{array}$ & $2(1.3 \%)$ & $25(16.7 \%)$ & $13(8.7 \%)$ & $49(32.7 \%)$ & $61(40.7 \%)$ \\
\hline \begin{tabular}{l} 
Source: Field Survey by John Boateng, 2014 \\
\hline
\end{tabular} & & & $18(12.0 \%)$ & $53(35.3 \%)$ & $66(44.0 \%)$ \\
\hline
\end{tabular}

Source: Field Survey by John Boateng, 2014

\section{Discussion}

\subsection{Learning Attainment}

This study has identified the major needs and accessibility issues that are of Importance to learners in the Central Region of Ghana. Specifically respondents have agreed in their responses that learning attainment ( the propensity for disabled learners to reach, or succeed in getting to the content, interacting with the content and learning appreciably from the e-learning experience) was an important issue to them. VITA (undated) identifies three things that instructional designers must do to design accessible e-learning course that meets accessibility standards and that appreciably improves learning attainment for all learners. Designing for effective interactivity, cautious use of analogies, examples and scenarios to engage learners in such a way that they can interact with the content being displayed and learn from the experience. Avoiding the use of analogies, examples and scenarios that are exclusive to non-disabled learners have been found to be helpful. For example, using examples like 'riding a bicycle' might not be perceived well by learners who are unable to ride bicycle because of their disability.

This might not help them to be engage appreciably so as to be able to learn meaningfully from the online learning experience. Similarly, the use of examples that depict 'seeing things' or 'hearing tunes or notes played from a musical instrument' might not effectively engage learners whose disabilities prevent them from being able to see or 
hear. Avoiding use of such examples, scenarios and analogies and using the kind that all learners (both disabled and non- disabled ones) can relate to, helps in enhancing learning attainment.

\subsection{Communication Handling}

Respondents in this study have agreed that, the way communication tools are used in the design of the web-based course are important in enhancing the accessibility of e-learning courses. This agreement, conforms to what the literature on accessibility upholds. VITA (undated) points out that, it is the responsibility of developers to ensure that all non-text elements have alternate text and that text descriptions should convey same information that is communicated by the corresponding images, movies, sounds and applets should also have Alt tags.

Using the appropriate color and the right contrast has been found to affect accessibility. It has been estimated that about $12 \%$ of men in are color blind (VITA, undated). Avoiding the use of wrong colors (green and red) and using the right colors with the right contrast matters in ensuring accessibility in e-learning. Moreover, to enhance accessibility, it has been suggested that any information conveyed through audio, multimedia format is also available in a text format via captioning or transcription (VITA, undated). When multimedia is used as a method of delivery, it is important to ensure that the content provided is suitable and accessibility standards are adhered to.

\section{Conclusion}

The paper explored the accessibility issues that were of significance to potential adult e-learners from the Central Region of Ghana. Among other interesting findings, the study has shown that, learning attainment (the propensity for disabled learners to reach, or succeed in getting to the content, interacting with the content and learning appreciably from the e-learning experience) and communication handling (the way communication tools are employed in the design of the web-based course) are important to assure accessibility.

Basically all means fell between 4.0 and 4.2. Looking at the frequency tables in Table 1 and Table 2 majority of respondents agreed that the issues raised are important to support e-learning for the disabled learners. Asunka (2008) study in Ghana showed that, a cross-section of Ghanaian students studied in a private tertiary school did not respond favorably to online constructivist teaching approaches such as asynchronous discussions and ill-structured projectbased learning activities, and perceived collaborative online learning within their context as a complex, more demanding and time-consuming experience.

The present study is confirming Asunka's findings that ill-structured project-based learning activities and perceived collaborative online learning within the learner context must have failed to address all or some of the above accessibility issues adult learners in Ghana consider important for effective e-learning. Findings from the study also tie in with Ndeya-Nderera (2012) beliefs that, implementation of learner-centred approaches that enhance learning are critical to ensure student success, particularly disabled learners. Based on the finding from the study and issues emerging from the discussion, it can be concluded that, increasing effectiveness in accessibility design could be achieved by providing among others, support for text browsing as well as providing simplified and consistent design presentation. Also providing screen enlargements, organizational areas, such as calendar, task list, address book and providing e-test versions of books will enhance accessibility.

Other tools to use to increase effectiveness in accessibility design will include, on-line help, and using alternative text for images, using appropriate color and contrast and employing accessible and consistent navigation technology. Designers should employ interactive elements that can effectively be integrated with assistive technologies. VITA (undated) report that the use of tool tips, mind maps and closed captioning for audio and video materials have used successfully to enhance effectiveness in accessibility design.

\section{References}

Asunka, S., 2008. Online learning in higher education in Sub-Saharan Africa: Ghanaian university students' experiences and perceptions. International Review of Research in Open and Distance Learning, 9(3): 1 -23.

Bugler, P., 2013. Empowering the disabled through e-learning. Retrieved from www.elearning-africa.com/eLA_Newsportal/empoweing-thedisabled-through-e-learning/ [Accessed 27th March, 2015].

Burgstahler, S., B. Corrigan and J. McCarter, 2004. Making distance learning courses accessible to students and instructors with disabilities: A case study. Internet and Higher Education, 7(1): 233-246.

Cooper, M., C. Colwell and A. Jelfs, 2007. Embedding accessibility and usability: Considerations for e-learning research and development projects. ALT-J, Research in Learning Technology, 15(3): 231 - 245.

Dell, C.A., T.F. Dell and T.L. Blackwell, 2015. Applying universal design for learning in online courses: Pedagogical and practical considerations. Journal of Educators Online - JEO, 13(2): 166 - 192.

Henry, S.L., 2001. Adapting the design process to address more customers in more situations. Proceedings of UPA (Usability Professionals Association Annual Conference. Retrieved from: http://www.uiaccess.com/upa2001a.html. [Accessed 3rd June 2016].

Henry, S.L., S. Abou-Zahra and J. Brewer, 2014. The role of accessibility in a universal web. Proceeding W4A 14 Proceedings of the 11th Web for All Conference.

IMS Global Learning Consortium, 2002. Guidelines for developing accessible learning applications. Retrieved from http://www.imsglobal.org/activity/accessibility [Accessed December 20, 2014].

Lincolnshire County Council, 2010. Definition of accessibility. Retrieved from http://www.lincolnshire.gov.uk/residents/environment-andplanning/environment/accessibility/definition-of-accessibility/56334.article [Accessed December 21, 2014].

Ndeya-Nderera, C., 2012. Research in progress presentation. Supporting online learning for all distance students especially students with disabilities. 1-4. Available from ODL-064-2012_Final_Ndeya-NdereraC.pdf [Accessed 27 th March, 2015].

Shneiderman, B., 2000. Universal usability. Communications of the ACM, 43(5): 85- 91.

Shojafar, M., S. Barzegar, F. Aeini and H. Rashidi, 2015. The practical guidelines for designing user interface in virtual learning environment. Int'1 Conf. e-learning, e-Bus, EIS.

Sloan, D., P. Gregor, P. Booth and L. Gibson, 2002. Auditing accessibility of UK higher education websites. Ineracting with Computers, 14(4): 313-325.

Valdes, L., 2003. Accessibility on the internet. Retrieved from http://www.un.org/esa/socdev/enable/disacc00.htm [Accessed 3rd June 2016].

VITA, undated. Developing accessible e-learning. Virginia Information Technology Agency (VITA) IT accessibility Toolkit. Retrieved from http://www.vita.virginia.gov/uploadedfiles/vita_main_public/library/accessibility/developingaccessiblee-learning.pdf [Accessed December 18, 2014]. 
WCAG, 2008. Web content accessibility guidelines (WCAG) 2.0. W3C recommendation. Caldwell, B., Cooper L., Reid, L.G., Vander heiden, G. (eds). Retrieved from https://www.w3.org/TR/WCAG20/ [Accessed 2nd June, 2016].

Wikipedia, 2016. Accessibility. Retrieved from https://enwikipedia.org/wiki/accessibility [Accessed 3rd June 2016].

\section{Structured practitioner notes}

What is already known about this topic?
i. $\quad$ people with disabilities encounter all the same problems that people without disabilities do
ii. The lower the level of accessibility of a resource for an individual, the less usable it will be for them
iii. $\quad$ improved accessibility for users with disability promotes usability for all
iv. Potential Ghanaian adult students studied did not respond favorably to online teaching approaches

What this paper adds
i. $\quad$ Online teaching approaches experienced by Ghanaian adult learners fails in accessibility considerations
ii. Designing for effective interactivity of learners will help connect learners with the content
iii. Cautious use of analogies, examples and scenarios will engage learners with and without disabilities effectively
iv. Effective use of communication tools will enhance accessibility to learners with and without disabilities Implications for practice and /or policy

i. Implementation of learner-centered approaches and support to enhance learning are critical for learner success, particularly learners with disability.

ii. Increased effectiveness in accessibility design

iii. Need for National policy or law on accessibility consideration for learners especially learners with disability 